\title{
Understanding Why Motorcycle Riders Do Not Comply with Traffic Control Signals in the WA Municipality in Ghana
}

\author{
Paul Kitson Baffour Asamoah ${ }^{1 *}$ Nicholas Kombonaah ${ }^{2}$ Eric Appiah Atiemo ${ }^{3}$ \\ 1. Centre for Settlements Studies, College of Art and Built Environment, Kwame Nkrumah University of \\ Science and Technology, Kumasi-Ghana \\ 2. Department of Urban Roads, Wa Municipal Roads Unit, P. O. Box 16, Wa, Upper West Region, Ghana \\ 3. Centre for Settlement Studies, College of Art and Built Environment, Kwame Nkrumah University of \\ Science and Technology, Kumasi-Ghana
}

\begin{abstract}
The study was conducted in the Wa Municipality to investigate the reasons why motorcycle do not comply with traffic control signals. Though traffic control signals exist to regulate the movement of motorists in the municipality, they are violated by motorists especially by motor and tricycle riders. It is therefore a worrisome phenomenon, thus becoming an increasing concern among the law enforcement agencies. This is particularly so due to the increasing motorization in the Municipality. Therefore, in finding reasons for this incidence, the study sought to achieve the following objectives; the causes of motorists' disobedience towards traffic control signals; the roles of road safety stakeholders in enforcing traffic control signals compliance and the challenges in enforcing traffic signal compliance. The study was informed by two theories namely; the Theory of Planned Behaviours (TPB) and Normative Social Influence Theory (NSIT). Also, the study was conducted using qualitative approaches to source, process and analyse data. As a result, the data was collected using Focus Group Discussions (FGD) approach to solicit information from both motor and tricycle riders. Interview Guides were additionally used to gather data from the heads of the stakeholder institutions and that of the various Tricycle Riders Associations concerned in this study. Subsequently, the data collected was analysed using thematic and Leximancer analysis approaches. However, the major findings from the study were that, traffic noncompliance by motorcycle riders is caused by the attitudes and behaviours of the motor riders though some of the respondents held a divergent view, with the popular saying that, "traffic do not catch natives" and that is why they violate road traffic signals, but upon further analysis, it came to light that, it is attitudinal. Also, the study reveals that, there is little or no enforcement of road traffic signs or laws. Those who commit these acts are not arrested and punished by the law enforcement agencies. Furthermore, it was interesting to find out that, most of the motorcycle riders, particularly the tricycle riders are ignorant about road traffic signs, and therefore the study recommends a proactive public education and sensitization on the awareness of traffic control signals as well as ensuring effective enforcement of the road traffic laws in the Municipality
\end{abstract}

Key words: motorcycle, control signals, disobedience, controlled intersections, law enforcement

DOI: $10.7176 /$ RHSS/9-14-17

Publication date:July $31^{\text {st }} 2019$

\section{Introduction}

This growing problem of motorist disregard for traffic control signals (TCSs) has become a major concern across the world (Susilo Lui \& Börjesson, 2015). These occurrences can be attributed to violation of traffic control signals and road safety regulations especially by motorists, cyclists and pedestrians (Chaikof et al., 2018; Ivana et al., 2017; Susilo, Joewono \& Vandebona, 2015). In developing countries, motorists and pedestrians often consider traffic laws violation as a minor issue though its consequences could result in terrible accidents, with consequent loss of lives, and damages on property (Zhang Tan \& Jou, 2016; Tunde, 2012).

In the spate of this increasing concern about road traffic non-compliance by motorist, it is only partially understood in developing countries like Ghana. Most of these problems which comes about as a result of road traffic violations are accidents but no studies have been done into details to unearth the reasons why motorist violates road traffic signs especially in the urban centres.

In countries such as India, Indonesia and other developing countries, motorcycles are increasingly becoming the common means of transport especially among low-income urban dwellers and the poor (Susilo Lui \& Börjesson, 2015). In the wake of the unsatisfactory state of affairs regarding public transport, private motorcycles have been a panacea to urban transport in Ghana (Amoako, Cobbinah \& Niminga-Beka, 2014). Though the increasing growth in the number of motorcycles has come to solve the mobility needs of many urban residents in the light 
of poor and inadequate public transport system. This has also come with its accompanying challenges such as non-compliance with road traffic regulations by motorist. These road user's behaviours have also been characterized by lack of certified training and valid licensing and indiscipline especially among the motorcycle riders, hence exposing them to road traffic accidents (Chalya et al., 2010). Although, there are multiplicity of factors that have been attributed to road traffic non-compliance particularly at signal controlled intersections, including geometric design, motor/vehicle conditions, the behaviour of motorists apparently is of relevance in this study since less attention has been paid to this in literature than is deserved. Relatively little is known about the characteristics of red-light runners and the circumstances which may prompt them to run a red light.

This study was therefore necessitated by the aforementioned behaviours of motor riders, hence, the need to understand why motorist do not comply with traffic control signals in the Wa Municipality.

Basically the study sought to: examine the causes of disobedience towards Traffic Control Signals in the Wa Municipality; find out the attitudes of motorcycle riders (MCR) towards Traffic Control Signals Compliance; examine the role of Road Safety Stakeholders in enforcing Traffic Control Signals compliance among Motorcycle Riders in Wa the Municipality; assess the challenges in enforcing Traffic Control Signals Compliance among Motorcycle Riders in the Wa Municipality.

\subsection{Significance of the Study}

The significance of this research stems from, among others, the reasons why motorist particularly the motor and tricycle riders do not comply with traffic control signals in the Wa Municipality. The findings of the study is expected to be useful in understanding the underlying factors influencing motorist non-compliance with traffic control signals particularly at the traffic intersections. Although the growth of motorcycles usage and its associated impact in the municipality are obvious, because of their affordability and accessibility, however, their activities have also been confronted with risky behaviours such as violating road traffic signs and regulations (Chalya et al., 2012). Therefore, an in-depth understanding of their attitudes and the motives behind such behaviours will aid in initiating traffic compliance measures in addressing this phenomenon. In addition, this study would lead to the realization of effective strategies and policies towards reducing traffic non-compliance and its attendant accidents.

\section{LITERATURE REVIEW AND THEORETICAL FRAMEWORK}

Many studies have examined the causes of road traffic non-compliance by motorist in the world over. But, there is no consensus on the reasons why these motorists do not comply with these signs. This section reviews literature review on key thematic areas which aimed at understanding why motorist do not comply with road traffic signs and laws in the Wa Municipality. The chapter starts with an evaluation of pertinent literature concerning the major themes; an overview of transportation modes and the concept of traffic law enforcement. Afterwards, the study looks at the traffic non-compliance in perspectives in developing countries including Ghana. Subsequently, it also looks at the various stakeholders' roles in enforcing traffic non-compliance, and as well as the effectiveness of the enforcement measures in addressing motor traffic non-compliance in the Municipality. The conclusion of the chapter then summarised the criticisms of the theories reviewed and as well as the research gap identified.

\subsection{Transportation modes in Ghana}

In developing countries such as Ghana, vehicle ownership is low and dependency on public transport is high but the financial conditions and performance of all forms of government-organized public transport are ineffective and are in decline (Kumar, 2011). This situation has forced people and the market to develop creative solutions to address daily travel needs, hence a resort to motorcycles for personal mobility to complement the public transport systems. However, in as much as the relevance of transportation cannot be under estimated, it is also saddled with road traffic non-compliance.

There are several types and models of motorcycles around the world. The preference of motor bikes is dependent on the quality and properties. They can be categorised mainly into two, namely two-wheeled and three-wheeled motorcycles. Three wheelers are generally used for passenger and good commercial transportation. Tricycles in 
Ghana, to a larger extent are used for freight transportation except in some few cases where they are used to convey passengers in rural areas (Dinye, 2012). Nowadays their scope of operations has been extended to the urban centres.

\subsection{Importance of traffic control signals}

Traffic control signals are the most visible elements of the urban road infrastructure. They are not just physical systems like telephones or sewers or streets, although their technological elements, traffic lights, signs and painted pavements fit that description. Rather, they are systems that attempt to impose a strong social control over the most fundamental of human behaviours, whether to move or be still. Traffic control signals regulate the movement of pedestrians, motorist and other streams of road users on the roads especially at the traffic intersections. For most other elements of the urban infrastructure, controlling the behaviour of motorist does not constitute the primary goal of designers. For traffic engineers, understanding and manipulating the behavioural patterns of motorist and pedestrians (a group that included not just walkers, but people using the street for play, social gatherings, and commerce) proved to be a more important problem than the control mechanisms themselves

\subsection{Concept of Traffic Law Enforcement}

According to the Organization for Economic Co-operation and Development (OECD) (1974; 2015), traffic law enforcement (TLE) is the area of activity intended at controlling road user behaviour. Human behaviour on the road needs to be controlled and regulated so as to reduce the rampant manifestation of road accidents, hence the essence of traffic control signals. Also, they are made to regulate the behaviour of individuals in a society so as to ensure conformity and reduce chaos among people interacting with one another in a society. Thus, it is for this reason that traffic laws were enacted to ensure sanity on the roads and perhaps reduce road fortunes.

In a similar vein, these Traffic laws are enforced by using three main measures namely, preventive, persuasive and punitive to effect a change in road user's behaviour to ensure efficient movement of traffic. These three measures are enforced by the law enforcing agencies in Ghana, which in most cases are the police and the DVLA officers so as to ensure that motorist put up the best of behaviour on the road and observe all traffic rules and regulations. Preventive traffic measures are traffic laws that are put in place to reduce and possibly prevent the occurrence of road accidents. Such measures include: Avoiding over speeding and avoiding drinking of alcohol whiles driving. All these measures are put in place as preventive measures to reduce the occurrence of road accidents. Persuasive measures on the other hand are more or less like preventive measures but the only distinction that can be drawn between them is that, persuasive measures in most cases do attract severe punishment but rather law enforcement agencies persuade road users to adopt such measures for their own safety. Punitive traffic laws are laws that specify the type of punishment associated with the violation of any traffic law. Punitive traffic laws differ in magnitude depending on the type of offence that motorist commits. These measures are put in place to deter road users from voluntarily disobeying traffic laws and encourage compliance of traffic regulations on the road. The traffic control signals that specify acceptable road user behaviour are important elements in the development of a safe road environment and it is the enforcement of these laws that is commonly regarded as one of the most effective means of moderating and reinforcing compliant road user behaviour (Elvik \& Vaa, 2004).

In advanced countries such as Norway, traffic law enforcement provides the means of modifying road user behaviour and this has been demonstrated to reduce a number of road injury accidents (Pennay, 2008). This is however different from developing countries such as Ghana where traffic non-compliance is very common especially among motorcycle riders in the Wa Municipality though there have been concerted efforts aimed at addressing this problem.

\subsection{Factors influencing non-compliance with traffic control signals by motorcycle riders}

Studies have indicated that several factors can influence the individual's willingness and ability to comply with traffic laws and regulations. Among these factors are the perceived risk of various riding/driving behaviour and legitimacy of laws and associated enforcements (McKenna, 2007), Sex and age (Oltedal \& Rundmo, 2006), motorist motive (Tyler, 1990), the deterrence effect (Sunshine \& Tyler, 2003), defiance and visibility of law enforcement agencies on the road. Another study by Kimwetich \& Ndunge (2012), to determine the level of compliance and awareness of traffic control signals among tricycle riders in Kitui town, only $2.2 \%$ of the 90 motorcycle riders knew traffic rules that governed their movement. The study further indicated that $97.8 \%$ of all 
the participants when asked to state traffic laws to be obeyed while on public roads gave sketch answers or never attempted to answer. This therefore has serious implications as far as road safety is concerned, thus it is necessary to unearth the reasons behind this behaviour. Also, although, there are several determinants of road traffic law compliance as mentioned above, but for the purpose of this study, sex, age and the motives of the motorists were employed. This was informed by the fact that they are relevant and are captured in the objectives of the study and will help in understanding non-compliance with TCS by motor riders.

\subsection{Effects of non-compliance with traffic control signals by motorcycle riders on the economy}

The impact of enforcement can be estimated as the potential accident savings resulting from having all motorists complying with all traffic laws and regulations all the time. It is evident that much of the compliance is voluntary or a result of successful socialization mechanisms not depending on active policing. Therefore, such estimates are the maximum value estimates for Traffic Law Enforcement (TLE) impact. The incidence of road traffic noncompliance by these riders has consequences of traffic fatalities and for that matter, their effects on the economy cannot be overlooked. This has led to loss of lives and therefore places hardships on the individuals and families that are mostly affected. Most road traffic injuries are as a result of non-compliance to road traffic laws, thus putting a heavy burden, not only on global and national economies but also household finances. Many families are driven deeply into poverty by the loss of breadwinners and the added burden of caring for members disabled by road traffic injuries (Peden, 2004). Also, the financial burden of increased death and injury severity can have a major impact on the finances of the government and local communities who are paying for the resources that are required to deal with road crash victims and their families in the aftermath of a crash. Everyone killed, injured or disabled by a road traffic crash has a network of others, including family and friends, who are deeply affected. It would be impossible to attach a value to each case of human sacrifice and suffering, add up the values and produce a figure that captures the global social cost of road crashes and injuries (Peden, 2004). The economic cost of road crashes which are usually the consequence of traffic noncompliance is estimated to be $1 \%$ of gross national product (GNP) in low-income countries, $1.5 \%$ in middle-income countries and $2 \%$ in high-income countries. In simple tense, road traffic deaths and injuries (RTIs) impose a huge economic burden on developing economies since resources that could have been channelled to other uses or sectors of the economy have to be spent on victims of road crashes particularly motorcycle riders and some of the accidents are often avoidable.

\subsection{Theoretical Grounds of motorcycle riders' non-compliance with traffic control signals}

A number of studies have attempted to establish the factors that causes road traffic non-compliance among motorist but not much has been established in the literature. However, the results clearly indicate the human element as the main cause. The common denominator of human errors seems to be lack of compliance by motorist to road traffic signs. As a result, a number of theories have over the decades been propounded to dilate on road traffic non-compliance. Among the theories known, a few relevant ones are useful in helping to develop a theoretical framework for this study. A theoretical framework serves as a means of defining and explaining the research problem (Jacard \& Jacob, 2010). In this framework two theories were drawn to understand why motorist do not comply with traffic control signals, the key variables that influences why they behave the way they do and how this could be minimised within the study Municipality. These theories are the Normative Social Influence Theory (NSIT) and the Theory of Planned Behaviours (TPB)

The Normative Social Influence Theory relates social influences to behavioural changes of a person which in turn, is influenced by perception of the actions of other people and society in general. The action of changing the behaviour for this theory is called as conformity. Conformity strategy is the process in social norms which people's beliefs or behaviours are influenced by peer pressure or unconscious compulsion. This theory believes that people take risks because of peer pressure or a general community perception that an activity is of low risk.

The Theory of Planned Behaviour that was developed by Ajzen (2011) has been widely used in studies related to risky behaviours. This Theory of Planned Behaviour (TPB) is the most used framework in the category of behavioural models (Morgan \& Bachrach, 2011). The main assumptions of the TPB are that, intention is a strong predictor of behaviour and intention may be assessed by evaluating general attitudes, beliefs and preferences. The three most important elements embedded in this theory are; attitude, subjective norms and perceived behavioural control but only two of them were highlighted in recent study. Traffic non-compliance which is entirely a behavioural or attitudinal, hence, this theory was drawn to help explain this study. Figure 2.1 shows the relationship between the components of the theory. 


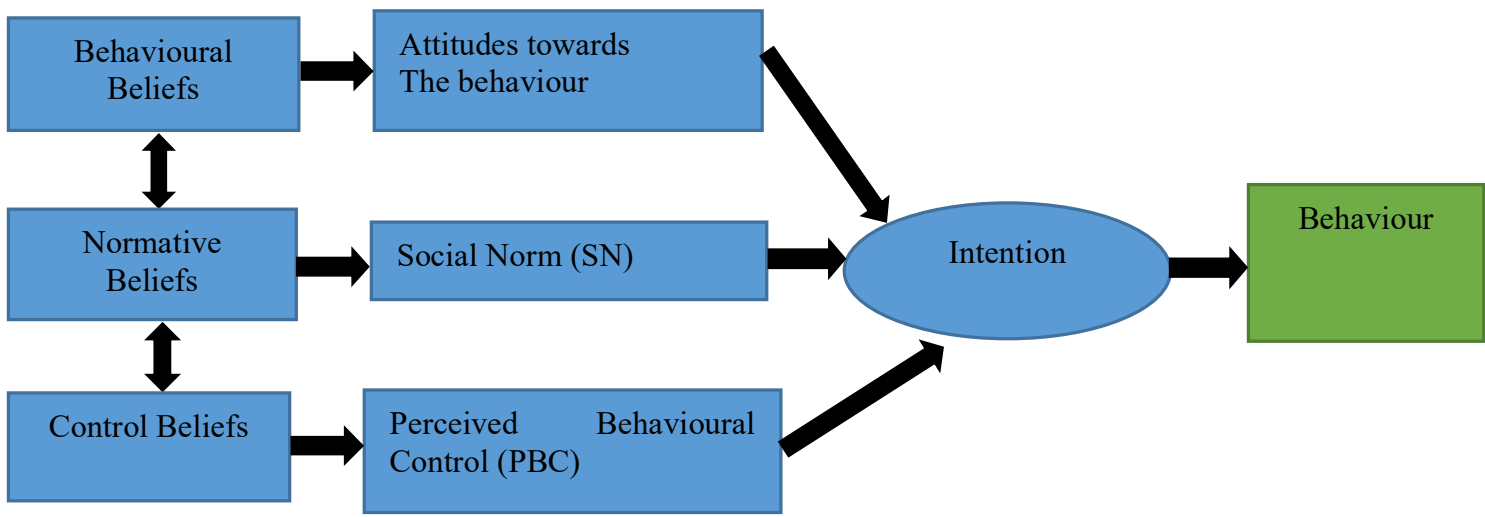

Figure 2. 1: The Theory of Planned Behaviour

Source: Adapted from Ajzen, (2011) and modified

Generally, the premises of the theory, therefore is that, volitional behaviour is based on intention and that intentions are based on three cognitive components: attitudes, SN and PBC which are embedded in this theory. The attitudinal component is the evaluation of the likely outcomes of the behaviour (what will happen if I do it?), subjective norm is the perception of the social norm surrounding the behaviour (what will people think if I do it?) and PBC is the perceptions of control over the behaviour (can I actually do it without too much trouble?). Thus these are the factors that influences one to either comply or not comply with road traffic signals.

Thus the constructs of the TPB have proven important in understanding the differences between safe and unsafe motor riders (or violators and non-violators) within the traffic safety literature. However, on the contrary it is argued that although the TPB has improved on road traffic accidents (RTA) most caused by traffic noncompliance by motorist, the improvement is not consistent with all behaviours. Most of the limitations suggested for the TRA, including lack of variables such as attitudes towards enforcement and emotion, also apply to the TPB (Delaney et al. 2004). For instance, despite the support given to the new variable (PBC), various authors criticized it for lack of clarity concerning its meaning (Fishbein \& Stasson, 1990, cited in Fletcher et al., 2006).

\subsection{Conceptual Framework of the study}

According to Kothari (2004), a conceptual frame work is defined as an abstract idea or a theory used to develop new concepts or to reinterpret existing ones. It shows the relationship between variables under study and how they influence one another in terms of the dependent and independent variables. For instance, age as a variable may be associated with high speeding and violation of traffic rules as established earlier on. Therefore, from the figure 2.3, the dependent variable is the motorcycle riders' non-compliance while the independent variables include; the behavioural factors or attitudes of the motor riders, rider's motives and that of the demographic characteristics that influences that willingness to either comply or not comply with road traffic signs and regulations in the Municipality. 


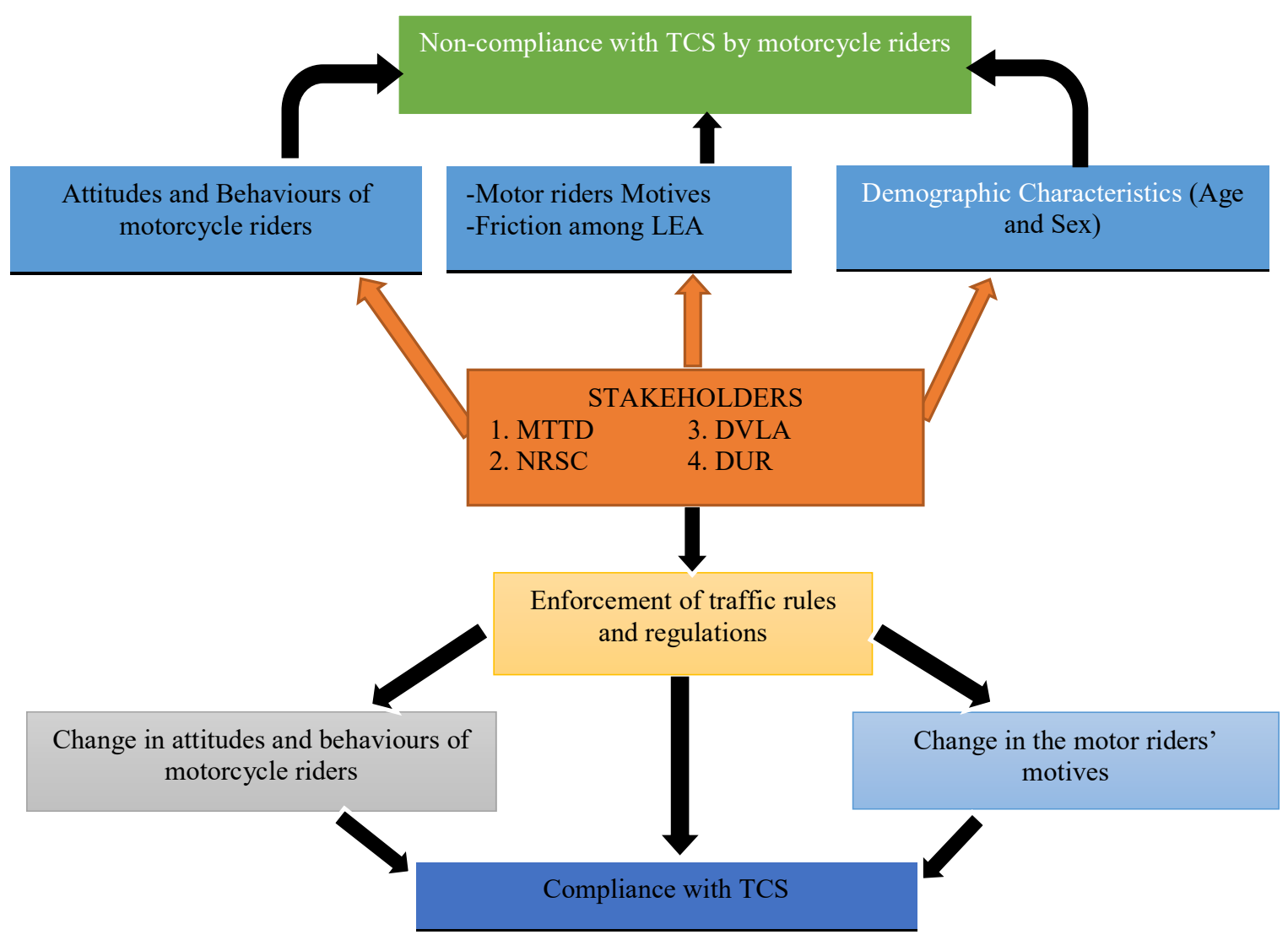

Figure 2.2: Conceptual Framework of the study

Source: Researcher's Construct, May 2018

Figure 2.3 gives the relationship between the independent and dependent variables. As seen from the conceptual framework, compliance to traffic control signals is influenced by road users' level of attitudes, their demographic characteristics and that of their subjective norms.

The studies have shown that road traffic violations are the riskiest type of aberrant riding behaviours. They are mediated by the attitudinal and motivational factors and make a significant contribution to the accident toll in the Municipality. Various social cognition models have been utilized in road safety research to theoretically explain the underlying psychological mechanism involved in commission of violations. However, from the foregone review of the studies done by various researchers globally. For example, Lankarani et al. (2014) and Dinye (2012) among others, all concentrated on road traffic accidents instead of non-compliance with traffic control signals instead of investigating reason for non-compliance.

\section{Methodology and Study Area Profile}

This section contains a description of the research methodology employed in carrying out the study and the profile of the study area. The Wa Municipality is one of the eleven municipalities that make up the Upper West Region (UWR) of Ghana. However, at the 2010 Population and Housing Census period, there were nine District/Municipalities in the region. It has an estimated population of 107, 214 people (Ghana Statistical Service, 2012). Its population is growing at the rate of $2.7 \%$ per annum with 71,051 of the population, representing 66.3\% living in urban Wa (Ghana Statistical Service, 2012). It also has a land area of approximately 234.74 square kilometres, which is about $6.4 \%$ of the region's total land area. Figure 3 shows the Wa Municipal boundaries and some selected major towns. 


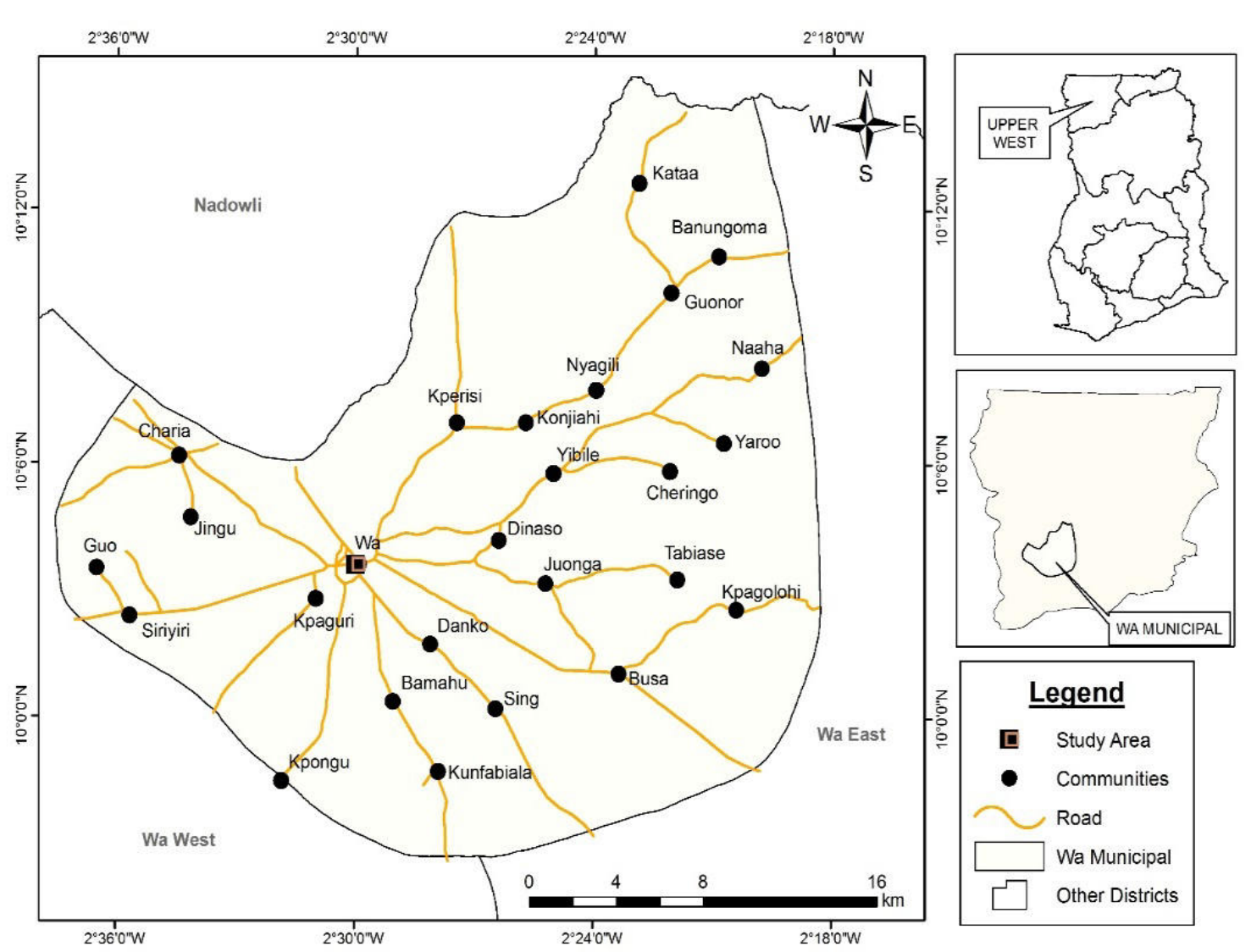

Figure 3. 1 Municipal Map of Wa

Source: Town and Country Planning Department, Wa (2018)

\subsection{Research Methodology}

The study made use of the case study design to guide the entire research process. According to Yin (2014), a case study is an empirical inquiry that investigates a contemporary phenomenon, which this study fits very well and was premised on the qualitative research approach, thus, aligned to the interpretism research philosophy.

The data sources included secondary and primary. The secondary sources included published and unpublished reports, journals materials, textbooks and magazines and articles. The primary sources were made of Focus Group Discussions (FGD), Participant Observation and as well as Interview Guides to solicit information from the identified institutions. Focus Group Discussions (FGD), Participant Observation and as well as Interview Guides to solicit information from the identified institutions.

The study targeted three set of respondents. The first set was the motorcycle riders within the selected zones of the Wa Municipality. The second set of the respondents were the leaders of the various tricycle riders associations, whereas the third group constituted the stakeholder institutions that are responsible for ensuring road safety in the Municipality. As part of the inclusive criteria, the study strictly considered the motor and tricycle riders. The study also considered those within the age brackets of between 18 and 35 years.

Since qualitative approaches were the main primary techniques for the data collection, it was therefore necessary to employ a qualitative approach for the analysis, hence the study employed thematic analysis together with the Leximancer software. 


\subsection{DATA ANALYSIS AND DISCUSSIONS}

\section{Awareness of Road Traffic Signals}

It was useful for the study to determine whether respondents had basic ideas about traffic regulations and the possible effects that their knowledge on traffic regulations could have on traffic compliance. As a result, data was collected from the motor and tricycle riders using FGD and interview guides as the main data collection instrument across the five zonal councils in the Wa Municipality on the awareness of road traffic signs. The study indicated that most of the motor riders in the municipality had little or no knowledge on the existence of road traffic signs. They were unaware of what such signs represent and how relevant they are to motor and tricycle riders. It was further revealed that, most of the motor riders were only aware of the traffic lights, but the other road traffic signs such as the "GIVE-WAY", "STOP" lines, and the "Zebra Crossing Signs" were less known to them. Again, the findings showed that, most of the riders only know the connotation of the Red Light (which means 'STOP') and that of the Green sign also (meaning 'GO'). This can be said to be a contributory factor behind their poor attitude towards road traffic signs as most of the motor riders are unfamiliar with them. For instance, when participants in a FGD held in Danko were asked about the meaning of the Zebra Crossings and the Stop Lines, it was interesting to notice that, most of the participants could not interpret their meanings. This was also affirmed by a male participant in Busa that;

"Hmm, I think the problem of traffic noncompliance is as a result of the motor riders not being familiar with the road traffic signs, there is no education on them. Some of our riders don't know the meanings of the red, blue and yellow signs of the traffic signals. Also the zebra signs are not known and I think that the government and the NCCE should educate the general public and our riders on the importance of the road traffic signs" (Interview no. 02-18/03/2018).

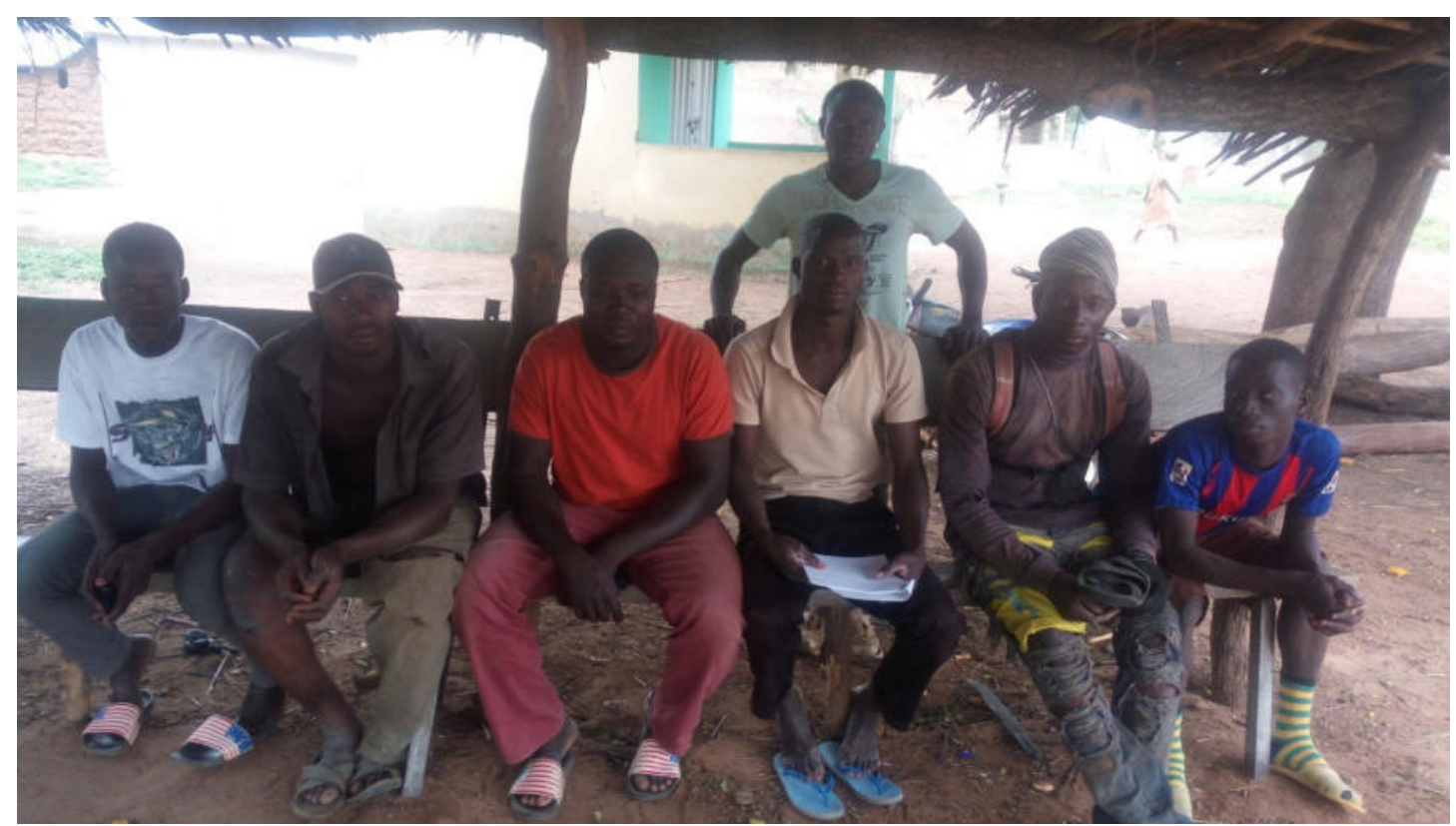

Plate 4. 1: A Picture showing an all-male participants during a FGD session in Busa

Source; Researcher's Field Work, March 2018

Though it was revealed from the various FGDs that, a good number of the motorcycle riders were not really aware of the road traffic signs, some of the participants disagreed with this view and asserted that motor riders deliberately refuse to comply with them, with the common notion that "natives" do not comply with traffic regulations. It was also obvious from the data available that, most of the motor riders in the study area are not familiar with the traffic control signals as indicated earlier and as a result, they are unable to read and interpret their meanings. The implication is that, these riders are more vulnerable to RTA than any other road users. 


\subsection{Mode of Training for Motor and Tricycle Riders}

The study identified two main modes of training before licensing namely, professional or formal training and informal training. The informal training mode is where motor/tricycle riders learn riding through apprenticeship, friends or family members without certificate from any accredited institution. On the other hand, the formal mode of Training is the process in which potential motor riders are taken through theory and practical by an authorized agency or its affiliate (DVLA) before a motor license is issued and it is renewable within a certain time frame. The study discovered that most of the motor riders were not formally trained on how to ride. The participants of the focus group discussion revealed that they learned riding through family members and friends who knew how to ride and were not aware that they need license to enable them ride. This was therefore contrary to the provisions in the Ghana Road Traffic Act, 2004 (Act 683).

According to the Road Traffic Act-2004 (Act 683), a motorcycle/tricycle rider must hold a current rider's license as well as a current registration. Also, part 16(1) clearly states that, a person shall not drive a motor vehicle on a road unless he is the holder of a license for the purpose (in this Act referred to as a "driver's or rider's license") and a person shall not employ any person to drive a motor vehicle on a road unless that person so employed is the holder of such a driver's license. These can be inferred from the excerpts from some respondents below;

"More than $80 \%$ of those who ride motorcycles in the Wa Municipality do not have license or undergo any training, they just learn how to ride the motor cycle and there they go" (Interview no. 01-17/03/18).

The above response from the field shows that, most of the riders in the municipality do not have motor license or training. Riding without license or any form of training by the motorists has implications on human lives and properties.

\subsection{Causes of disobedience towards Traffic Control Signals}

A number of risk factors contribute to road traffic noncompliance and the resulting human casualties. These road user behavioural factors as outlined in the conceptual framework are the most common factors, accounting for more than $85 \%$ of all traffic crashes (Odero Khayesi \& Heda, 2003). They have also been explained under the Theory of Planned Behaviour (TPB) as the central theme of the study. Some of these causes of road traffic disobedience in the study area are: lack of training and awareness on traffic control signals, ignorance towards road traffic signals, indiscipline on the part of riders, weak of enforcement of road traffic laws and regulations, attitudes of motorcycle riders in the municipality, minors riding motorcycles, the use of hard drugs/ alcohol abuse and the presence of police officers at traffic intersections. It was revealed from the responses of the motor riders that the presence of the police officers at the various traffic control points cause them to violate these signs for fear of been caught if they stop. For instance, out of the Ten (10) participants who were present during a focus group discussion in Charia, 9 of them referred to the presence of the police at the various traffic intersections as the reasons why they violate the traffic control signal. See the excepts below;

"The police should not harass motorists at traffic intersections. It is because of the police that motor riders disobey the red signs of the traffic light since they normally fear of been caught should they stop" (Interview no, 07-25/03/18).

Similarly, response from the police department to an extent confirmed this.

Generally, it can be observed that from the above excerpts that, the use of hard drugs by some section of the motorcycle riders in the Municipality influence their behaviours towards road traffic laws and regulation. The implication is that, if the Police MTTD does not ensure effective traffic law enforcement, the outcome would be disastrous since innocent lives would be lost as a results reckless road behaviours by these motorcycle riders.

\subsection{Effects of road traffic non-compliance by motorcycle riders}

Besides examining the causes of traffic disobedience among motor users (motor cycle and tricycles), the study also identified the possible effects of non-compliance in the Municipality through the information and observations gathered from the field. The data from both the Focus Group Discussion and the Institutions clearly attributed the causes of traffic non-compliance by motor riders to human behavioural factors such as accidents which at times results in loss of lives and other financial and psychological strain brought to bear upon the 
bereaved families. It also burdens the government financial commitments and other services that could have been channelled to other areas of national development.

It could therefore be implied from the responses and observations gathered from the study that the effects of traffic noncompliance by motorists are devastating on the lives of individuals and the Municipality as a whole. Thus, in an attempt to minimize its effects, there is the need to sensitize and educate the motorist on the relevance and the need to comply with road traffic signs. Additionally, the law enforcement agencies such as the Police should be proactive in arresting and prosecuting traffic law offenders in order to serve as deterrent to others.

\subsection{Stakeholders Roles in enforcing Traffic Control Signals (TCS) in the Wa Municipality}

Institutions play a very important role in ensuring traffic compliance in the Municipality and Ghana as a whole. Henceforth, the study identified four key institutions that are responsible for the education, enforcement and maintenance of road safety in Ghana. These institutions are basically the MTTD, DVLA, and NRSC. Each of these institutions are entities on their own but they collaborate with each other to offer training to the motorist and also to check unauthorized road users from the road though in most cases individual organization do their own programs due to differences in the outline and functions.

\section{Results of Leximancer analysis and discussions}

The results of some central themes were further subjected to the Leximancer software to scientifically confirm or otherwise from what was manually analysed.

The results of the socio-economic characteristics using the automatic mapping function of the Leximancer software. The arrow pathway that links "SCHOOL" to "PAY" via "DAILY" and to "MOTORCYCLE" concepts are clustered within overlapping themes. The dominant theme is "SCHOOL" with a word count of 5 as also shown in the figure above as against "PAY" and "DAILY" which has a word count of 3 each. They are also linked by "MOTORCYCLE". The implication is that; education plays an important role as far as road traffic signals compliance is concerned. As evident from the field that most motor riders especially the tricycle riders could not understand and interpret the meaning of these road signs because they are uneducated, therefore they violate them unknowingly. Most of them dropped-out of school at the basic level and others too had never been to school, as a result they are unformed about road traffic laws and their implications. This is why "SCHOOL" has been dominant and therefore has the largest word count of 5. Also, most of the participants during the focus group discussions indicated that they had dropped-out of school at the basic level to take up the tricycle businesses so as to earn a living. These are mostly the tricycle riders and so they are ill-formed about road traffic signs.

It can be deduced from the data collected that traffic signals are not known to most of the motorcycle riders since results from Figure 4.2 appear to re-affirm the same assertion as shown in the diagram. The major themes that emerged from the data are "KNOWN", "SIGNS" and "TRAFFIC" with word of 4 each as shown at the right hand side of Figure 4.2. This also supports an earlier assertion made by one of the respondents in the field that, some of the motor riders in the Municipality are very much aware of the existence of road traffic signs but however violates them and that is why "KNOWN" has dominated in the figure above. Also, though majority of the riders are ignorant of road traffic signs but some of the riders knows these traffic laws and signs. The theme with the highest word count also shows its relevance as far as the study is concerned, "TRAFFIC" as seen above has been key in this study and almost every participant made mention of it during the FGD sessions as compared to the other components shown on the diagram. 


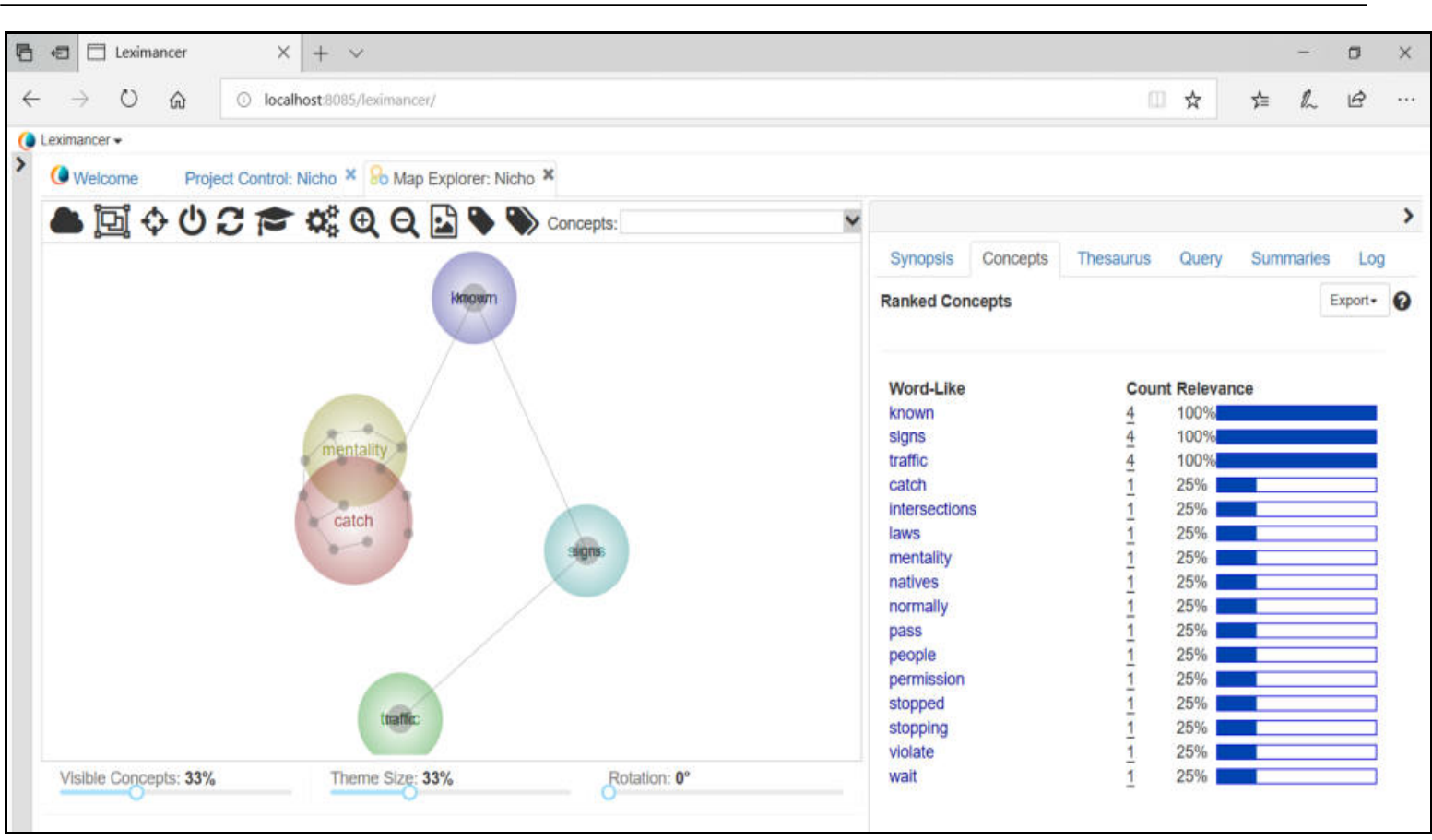

Figure 4. 1: Results of Leximancer analysis of data showing the Awareness of Road Traffic Signals and their ranked concepts.

Source: Field Work, August 2018

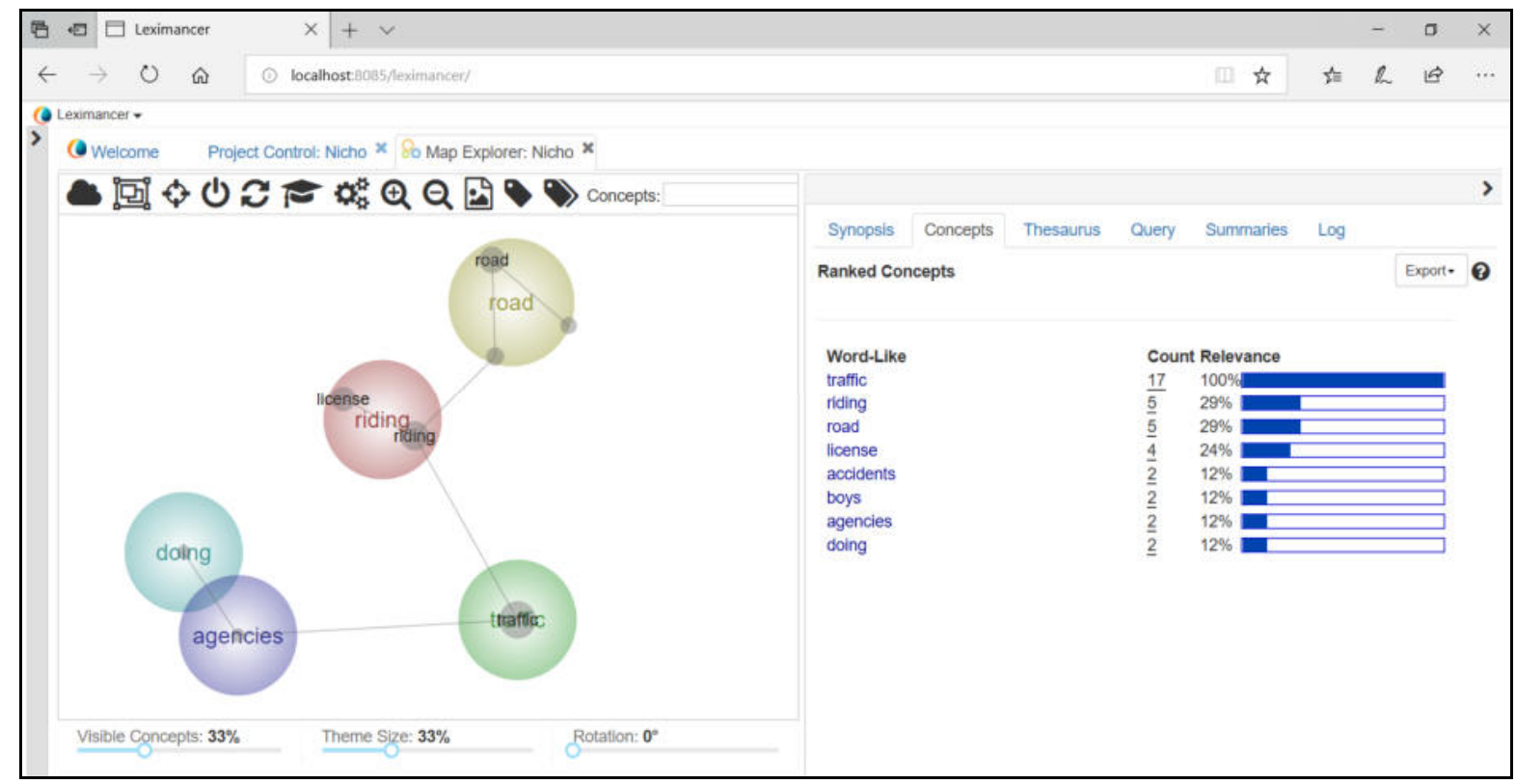

Figure 4.2: Results of Leximancer analysis of data showing the Causes of Road Traffiic Violations by Motorcycle Riders and their ranked concepts.

Source: Field Work, August 2018 
Figure 4.3 shows all the ranked concepts indicating their frequency of occurrence and their relevance. It can be seen that some of the main concepts with the highest number of occurrences and relevancy include such concepts as "TRAFFIC", "RIDING", "ROAD", and "LICENCE". The concept "TRAFFIC" occurs very frequently because it is often used in combination with the other concepts: for example, "Traffic Noncompliance"; "Road Traffic Signs"e, "Awareness on Road Traffic Signs", "Effects of Traffic Noncompliance" etc. This is to be expected since this thesis concerns itself with Traffic noncompliance and it dominated the discussions during the FGDs and the other stakeholder institutions. On the diagram as is showed on the right hand side has a word count of 17, which shows the relevance of traffic as far as this study is concerned. The stakeholder in this study agencies are responsible for the enforcement of road traffic laws to regulates the riding behaviours of motorist on the road through the training of potential and issuance of rider's licensees and also educating them on the relevance of these road traffic laws. Thus, their reoccurrences on the concept map as they are interlaced by the arrows. For instance, on the concept map the most of the participants indicated that the agencies that are responsible for ensuring compliance with road traffic signs are do not perform their duties as expected of them. During the FGD, the participants held the view that the MTTD are not enforcing the traffic laws by arresting and prosecuting road traffic offenders, thus the cause of traffic non-compliance by motorist in the Wa Municipality. Hence, the clustering of "AGENCIES" and "DON'T" as seen on the concept map.

Similarly, most of the respondents during the data collection process believes in the common notion that, "traffic do not catch native", though when this was subjected to further investigations, it was revealed that, the problem of traffic noncompliance by motorist has to do with the attitudes and behaviours of the motor riders. This has also been established earlier on during the manual analysis as one the major causes of traffic non-compliance since the willingness to either comply or not comply with road traffic signal is mainly controlled by their beliefs and attitudes. Also the other agency that was criticised by the participants was the DVLA. They lamented that, the processes in the acquisition of motor licences are too laborious and expensive, therefore process should be made flexible and easy as it is the only place that motorist are trained on the relevance of road traffic signals. Therefore, the clustering of these themes shows their relative relevance on the problem under study as shown in figure 4.3.

The Leximancer analysis ranked the themes in terms of the connectivity and relevance. The ranked themes were "DESIGN", "DUR", "ROAD LINE MARKINGS", "TRAFFIC", and "PROACTIVE". These were the main themes within which the related concepts were clustered, implying their dominance during the focus group discussions. The concepts that are dispersed randomly in the analysis using Leximancer act like attractive forces to guide concepts to their resting places whereas the concepts clustered together on the map are related or tend to occur in similar contexts. The reoccurring themes have word count of 12 and this re-affirmed the data manually analysed that traffic noncompliance by motorcycle riders is partly blamed on the stakeholder institutions-MTTD, NRSC and the DVLA. The data further indicated that, the law enforcement agencies are not "PROACTIVE" in the performance of their duties, since they were rated below average. This view was held by all the participants that took part in the discussion at Busa, thus its dominance within the themes.

\subsection{Challenges in enforcing Traffic Control Signals Compliance}

Despite the importance of these institutions concerning traffic enforcement, a number of challenges were identified during by the study which include limited qualified skilled staffs to manage the technical roles assigned to the institutions. For example, the Ghana Police Service is under staffed with police civilian ratio of 1:860 instead of 1:500 recommended by the United Nations. Within the Wa Municipality, there are only 43 police service personnel for all duties. The Service therefore finds it difficult to enforce compliance of traffic control signals. In addition to this is the problem of inadequate logistics such as vehicles, office space and accommodations and machines to check speed and alcohol levels of motor riders. Others are inadequate funding, interference from politicians, opinion leaders, chiefs and people at higher positions. Additionally, delays in the adjudication of traffic offences in law courts was also a major challenge. For motor riders to comply or not comply with traffic control signals is largely determined by the socio-demographic and other factors.

\section{Findings, conclusion and recommendations}

The study identified the following key findings based on the study objectives. The first objective of the study was to examine the causes of disobedience towards traffic control signals in the Wa Municipality. The causes were ineffective and weak enforcement of the road traffic laws by the MTTD and other road sector agencies, lack of awareness of road traffic signs and riding of motorcycles by minors. The second objective was to assess the attitudes of motorcycle riders towards traffic control signals compliance in the study site. The qualitative 
Leximancer software revealed that, noncompliance with traffic control signals by motorcycle riders were caused by the attitudes and behaviours of those riders. Though the respondents indicated that, it is only those from the villages who obey road traffic regulations such as the red light signal of the traffic lights, but upon further analysis, it came to light that, it is attitudinal. The third objective was to examine the role of road safety stakeholders in enforcing traffic control signals among motor cycle riders. The institutions identified by this study were the DUR, MTTD, DVLA and NRSC. These agencies have their roles ranging from road construction and maintenance to enforcement of road laws, monitoring and evaluation of road safety measures, issue license, education on road safety issues to providing in-service training for both riders and drivers. The performance of these institutions and agencies were unsatisfactory and their activities were not visible to the general public. The final objective of the study was to uncover the challenges encountered by the law enforcement agencies in enforcing traffic control signals compliance among motorists. The study identified inadequate financial resources and logistical constraints from the central government which inhibited them from effectively carrying out their mandates. The funds were irregular. In addition, lack of logistics such as speed /alcohol detectors and patrol to monitor motor cycle riders to ensure compliance with traffic control signals. Finally, these institutions were also under staffed and therefore were operating under their establishment.

\subsection{Recommendations}

To be able to address the problem of traffic non-compliance by motor riders in the Wa Municipality, the following measures are recommended. These include; 1) embarking on effective public education and sensitization on the awareness of road traffic signs and regulations, 2) effective enforcement of road traffic laws by the MTTD and their collaborative agencies, 3) there is the need for attitudinal change by motorcycle riders towards traffic control signals, 4) establish and implement a spot fine policy for road traffic offenders, 5) provision of financial and logistical resources/support to the law enforcement agencies and finally 6) the establishment of motorcycle training institutes to complement the works of the DVLA.

\subsection{Conclusion}

If the causes of increasing road traffic noncompliance are mainly attitudinal and emanating from indiscipline by road users as evident from the field data, then there is the need to refocus attention on behavioural change. Singapore can be a model for a study since they have been able to reduce human errors associated with unsafe road user behaviour. 'Safer Road Singapore' (2013) have changed the culture of road users to one where safe and courteous road use is instinctive and habitual by embarking on the three elements of road safety educationbasic, continuous and corrective education. Also, the study shows that beliefs and attitudes of the motorcyclist, social norms and perceived behaviour control significantly influence the intention to disregard traffic regulations and subsequently develop repetitive traffic violation behaviour. In line with previous studies in developed countries, 'belief and attitude' is found to be the strongest factor influencing the intention of motorcycle riders to disregard traffic regulations in the three cities studied. However, taking into consideration the culture in Wa, it is not really confirmed whether attitudes are the only reasons for road traffic violations. This finding highlights an important question that begs further investigation.

Similarly, due to data availability, the current study only focused on the factors influencing traffic signal violations in the study area, and did not take the road and mechanical factors such as the nature of the road, state of the motorcycle, speeding, and driving under the influence of alcohol, into consideration, though these factors are deemed important. Furthermore, future work can expand geographically to include other Municipalities of Ghana to obtain more comprehensive and comparable conclusions.

\section{REFERENCES}

Ajzen, (2011). The Theory of Planned Behaviour. Organizational Behaviour and Human Decision Process. Journal of Psychology and Health, 26(9), 1113-1127. [Online] Available: https://www.google.com/search?client=firefoxd\&q=+The+theory+of+planned+behaviour

Amoako, C., Cobbinah, P.B., Niminga-Beka, R. (2014). Urban Infrastructure Design and Pedestrian Safety in the Kumasi Central Business District, Ghana. J. Transp. Saf. Sec. 6(3), 235-256. [Online] Available: http://dx.doi.org/10.1080/19439962.2013.861887. DA: 10 ${ }^{\text {th }}$ April, 2017.

Chaikof, E. L., Dalman, R. L., Eskandari, M. K., Jackson, B. M., Lee, W. A., Mansour, M. A., \& Oderich, G. S. (2018). The Society for Vascular Surgery Practice Guidelines on the care of Patients with an Abdominal Aortic Aneurysm. Journal of Vascular Surgery, 67(1), 2-77. 
Chalya, P. L., Mabula, J. B., Dass, R. M., Mbelenge, N., Ngayomela, I. H., Chandika, A. B., \& Gilyoma, J. M. (2012). Injury characteristics and outcome of road traffic crash victims at Bugando Medical Centre in Northwestern Tanzania. Journal of Trauma Management \& Outcomes, 6(1), 1-10.

Chalya, P. L., Mabula, J. B., Ngayomela, I. H., Kanumba, E. S., Chandika, A. B., Giiti, G., \& Balamuka, D. (2010). Motorcycle injuries as an emerging public health problem in Mwanza City, Tanzania: A call for urgent intervention. Tanzania Journal of Health Research, 12(4), 214-221.

Delaney, A., Lough, B., Whelan, M., \& Cameron, M. (2004). A review of mass media campaigns in road safety. Monash University Accident Research Centre Reports, 220, 85. [Online] Available: https://www.monash.edu/muarc/our-publications/muarc220. DA: 19 $9^{\text {th }}$ June, 2017.

Dinye, R. B. (2012). Motorized Transportation in the Urban Areas in Northern Ghana: The Case of Motorcycle in Wa Township. Centre for Settlements Studies, KNUST. [Online] Available: https://urbanauapp.org/wp-content/uploads/dinye.pdf. DA: $3^{\text {rd }}$ March, 2017.

Elvik, R., \& Vaa, T. (2004). The Handbook of Road Safety Measures. EJTIR, 4(4), 445-446.

Fishbein, M., \& Stasson, M. (1990). The Role of Desires, Self-Predictions, and Perceived Control in the Prediction of Training Session Attendance. Journal of Applied Social Psychology, 20(3), 173-198.

Fletcher, J. P., Baguley, C. J., Sexton, B., \& Done, S. (2006). Road accident modeling for highway development countries. Main Report Trials in India and Tanzania. Report No. PPRO95. [Online] Available: https://www.monash.edu/ muarc/our-publications/muarc220. DA: $19^{\text {th }}$ May, 2017.

Ghana Statistical Service (2012). Population and Housing Census 2010. Ghana Accra. Government of Ghana. [Online] Available: $\quad$ http://www. $\quad$ Stats $\quad$ ghana. gov.gh/docfiles/2010phc/2010_Population_And_Housing_Census_Final_Results.pdf. $\quad$ DA: $12^{\text {th }}$ December, 2017.

Ghana Statistical Service (2013a). 2010 Population and Housing Census. (Regional Analytical Report, Upper West Region). Ghana Accra. Government of Ghana. Available: http://www.statsghana.gov.gh/ docfiles/2010phc/2010 Population and Housing Census.pdf. DA: 12 $2^{\text {th }}$ December, 2017.

Ghana Statistical Service (2013b). 2010 Population and Housing Census. (National Analytical Report of Final Results). Ghana Accra. Government of Ghana. Available: http://www.statsghana.gov.gh/docfiles/2010phc/ and housing Census Final Results.pdf. DA: 12 $2^{\text {th }}$ December, 2017.

Ivan, J. N., McKernan, K., Zhang, Y., Ravishanker, N., \& Mamun, S. A. (2017). A study of pedestrian compliance with traffic signals for exclusive and concurrent phasing. Accident Analysis \& Prevention, 98 (3), 157-166.

Jacard, J., \& Jacob, J. (2010). Theory construction and model-building skills: A Practical Guide for Social Scientists. New York, NY: Guilford Press. [Online] Available: http://ijhe.sciedupress.com DA: $11^{\text {th }}$ August, 2018

Kimwetich, C. J., \& Ndunge, D. (2012). The Influence of Urban Transport Policy on the Growth of Motorcycle and Tricycles in Kenya. In AIBUMA Conference. [Online] Available: https://profiles.uonbi.ac.ke/dorothyndunge/publications/'-influence-urban-transport-policy-growthmotorcycle. DA: $19^{\text {th }}$ February, 2017

Kothari, C. R. (2004). Research Methodology: Methods and Techniques. New Age International.

Kumar, A. (2011). Understanding the Emerging Role of Motorcycles in African cities: A political economy perspective. [Online] Available: http://documents. worldbank.org/curated/en/ 391141468007199012/Understanding-the-emerging-role-of-motorcycles-in-African-cities.

Lankarani, K. B., Heydari, S. T., Aghabeigi, M. R., Moafian, G., Hoseinzadeh, A., \& Vossoughi, M. (2014). The impact of environmental factors on traffic accidents in Iran. Journal of Injury and Violence Research, 6(2), 64-71.

McKenna, F. P. (2007). The perceived legitimacy of intervention: A key feature for road safety. Improving traffic safety culture in the United States: The journey forward. Washington, DC: AAA Foundation for Traffic Safety, 165-75.

Morgan, P. S., \& Bachrach, C. A. (2011). DEMOGRAPHIC DEBATE - Is the Theory of Planned Behaviour an appropriate model for human fertility? Vienna Yearbook of Population Research, 9, 11-18. doi:10.1553/populationyearbook2011s11

Odero, W., Khayesi, M., \& Heda, P. M. (2003). Road traffic injuries in Kenya: magnitude, causes and status of intervention. Injury control and safety promotion, 10(1-2), 53-61.

Oltedal, S., \& Rundmo, T. (2006). The Effects of Personality and Gender on Risky Driving Behaviour and Accident Involvement. Safety Science, 44(7), 621-628. 
Organisation for European Economic Co-operation (OECD). 2015 Annual Report, Paris- France. [Online] Available: https://www.oecd.org/newsroom/34011915.pdf DA: 11 th August, 2018.

Peden, M. (2004). World Report on Road Traffic Injury Prevention. [Online] Available:

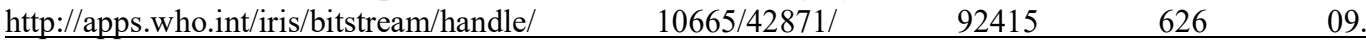
pdf;jsessionid=7AE85D9F838BA35EA59288CE14E49F63? DA: $3^{\text {rd }}$ March, 2018.

Sunshine, J., \& Tyler, T. R. (2003). The role of procedural justice and legitimacy in shaping public support for policing. Law \& Society Review, 37(3), 513-548.

Susilo, Y. O., Joewono, T. B., \& Vandebona, U. (2015). Reasons underlying behaviour of motorcyclists disregarding traffic regulations in urban areas of Indonesia. Accident Analysis \& Prevention, 75(3), 272-284.

Susilo, Y. O., Liu, C., \& Börjesson, M. (2015). Different Activity-Travel Participations of Different Generations in Different Life Cycle Stages of Women in Sweden (No. 15-1485). [Online] Available: https://ideas.repec.org/p/hhs/ctswps/2018 008. html DA: $6^{\text {th }}$ March, 2018.

Tunde, A. G., Taiwo, O. A., \& Matanmi, O. G. (2012). Compliance with road safety regulations among commercial motorcyclists in Nigeria. Canadian Social Science, 8(1), 92-100.

Tyler, T. R. (1990). "Why People Obey the Law. New Haven". CT, US: Yale University Press.

Yin, R. K. (2014). Case Study Research and Applications: Design and Methods. Sage Publications.

Zhang, G., Tan, Y., \& Jou, R. C. (2016). Factors influencing Traffic Signal Violations by car drivers, cyclists, and pedestrians: A case study from Guangdong, China. Transportation Research Part F: Traffic Psychology and Behaviour, 42(4), 205-216. 